\title{
DYNAMIC ROUTING OF WIRELESS ELECTRICAL SENSORS BASED ON NEURAL NETWORKS
}

Ju. Yamnenko, Yu. Khokhlov, O. Redko,

National Technical University of Ukraine "Kyiv Polytechnic Institute", 37, Prospect Peremohy, Kyiv, 03056, Ukraine.

e-mail: petergerya@yahoo.com

A method of dynamic routing based on the operation principles of neural networks, which allows to improve wireless sensor network by using an additional mechanism of error level accounting on routes. This method allows to dynamically monitor the quality of routes and select optimal routes. References 6, tables 2, figures 2.

Keywords: wireless, sensor network, dynamic routing, IEEE 802.15.4, neural network, automation, optimization

Introduction. Through the further development of microelectronics is possible to organize a new interaction of electronic and computer systems with the environment. In particular, in dealing with such problems as seismic and structural monitoring, biotelemetry, climate parameters monitoring, industrial and home automation, technology of a distributed wireless sensor networks (WSN) becomes popular [1]. Miniature WSN-sensor measures and transmits acquired data through a self-organized radio network [2]. The main advantage of WSN network is low energy consumption and simple schematics, which provide long battery life and low cost. On the other hand, the need to provide low power consumption imposes limits on a number of algorithms and on speed of WSN radio. It is particularly urgent task of developing efficient dynamic routing protocol (DRP), which requires significant computing resources and rapid communication channel. Dynamic routing task can be considered in terms of electrical engineering as analogue of least total electrical resistance definition for achieving of maximum current between the nodes under the assumptions that: a) electrical resistances of the branches change stochastically but are defined before decision making, b) after the decision making each node is only one input and one output current that is provided by corresponding branch commutation [6]. Thus, decision making about the way for current flowing and consequently about the route for signal transmitting is defined by corresponding commutation of electrical circuit branches.

The most important step of DRP protocol is to build a routing table based on a quality score of the communication between the individual nodes. In this article DRP which based on principles of neural networks is proposed. WSN that use such DRP will be able to recognize the best routes in constantly changing environmental conditions.

Construction of routing tables. Dynamic routing involves finding the best route of data transmission among several possible that involves the evaluation of routes quality. Two solutions of this problem proposed:

a) evaluation of communication quality by arbitrary scale;

b) evaluation of communication quality depending on the distance between nodes.

Real working WSN network can be represented as a complete graph, where each peak corresponds to the node and each edge corresponds to the existing direct link between the individual nodes. Quality of the link evaluated by arbitrary scale. Fig. 1 shows an example of the graph, and evaluations of the communication quality are summarized in Table 1.

Evaluation of quality of communication is usually conducted as a probability level of erroneously received bit (bit error rate - BER) $p_{e}$ or packet error rate (PER) $p_{p}$.

The expected value of PER can be represented as

$$
p_{p}=1-\left(1-p_{e}\right)^{N},
$$

where $N$ - number of bits in the packet.

For small values of BER and the condition of independence of errors in packets formula (1) can be represented as follows:

$$
p_{p} \approx p_{e}^{N}
$$

Depending on the purpose of network acceptable range PER values is specified: $P \in\left[p_{1} \cdots 1\right]$, where $p_{1}-$ the limit value of PER. The range is divided into three arbitrary characteristics: «missing link» $-P \in\left[0 \cdots p_{1}\right)$, «satisfactory link» $-P \in\left[p_{1} \cdots 1\right)$, «good link» $-P=1$. In practice, the scale can have more gradation marks. Arbitrary rating is assigned to each characteristic.

(C) Yamnenko Yu., Khokhlov Yu., Redko O., 2016

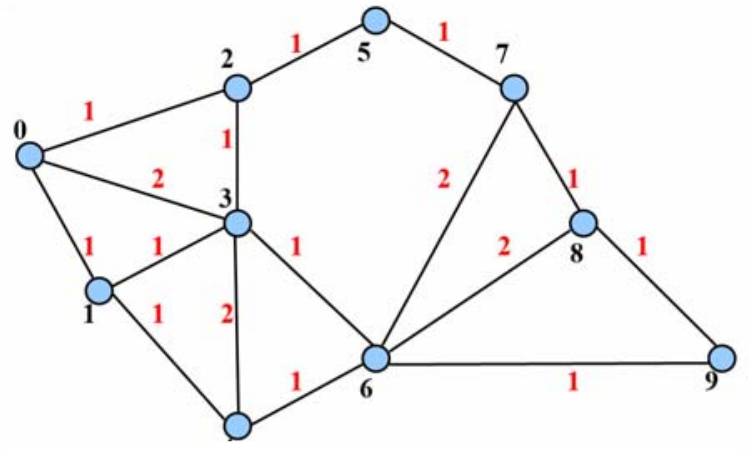

Fig. 1

\begin{tabular}{|c|c|c|}
\hline Communication quality & PER Range & Score \\
\hline Missing link & $P \in\left[0 \cdots p_{1}\right)$ & 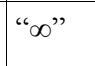 \\
\hline Satisfactory link & $P \in\left[p_{1} \cdots 1\right)$ & "2” \\
\hline Good link & $P=1$ & "1" \\
\hline
\end{tabular}

Table 1 
Analysis of WSN network graph allows to identify all possible routes of data transferring and estimate the total length of data path. For example, between the node №0 and №9 there are several possible routes listed in the table 2 .

In assessing the transmission quality on an arbitrary scale the best route will meet the condition:

$$
\left.\min \left(\sum_{i=1}^{n} P_{i}\right)\right|_{P \neq 2},
$$

where $i$ - graph edge; $P_{i}$ - score of $i$-th edge; $n$ - number of edges.

You can also add a condition of a minimum number of nodes in the route

$$
\left.\min \left(\sum_{i=1}^{n} P_{i}\right)\right|_{P \neq 2,(n+1) \rightarrow \min },
$$

where $(n+1)$ - number of graph nodes.

Route 5 will be the best from the routes listed in the Table 2.

The second method of the data quality assessment is based on the distance between nodes. The distance is determined by the time

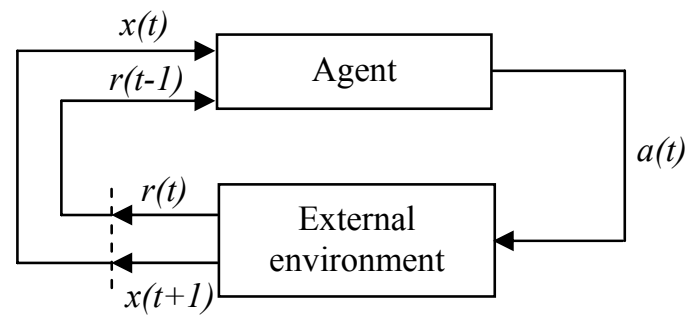

Fig. 2 of response of the adjacent node for the hallo-packet. Hallo-packet is a packet that used to establish belonging to neighbors. So instead of arbitrary evaluation, all edges of the graph are characterized by specific time intervals that measured by microcontroller timer for each node.

The best route by time interval assessment will be a route that meets the condition:

$$
\left.\min \left(\sum_{i=1}^{n} T_{i}\right)\right|_{(n+1) \rightarrow \min }
$$

where $T_{i}$ - time score of $i$-th edge.

In the case of low-speed sensor networks raises the need for a comprehensive approach to assessing the quality of communication, as the score only of the metric or errors can lead to severe degradation of the system due to sub-optimal use of its resources.

Traditional DRP protocols (OSPF, BGP) [3] [4] provide transmitting of packet by the optimal route, and when this is not possible, then the next most successful. That is, even if the best route can't provide reliable transmission of information over time, node

Table 2

\begin{tabular}{|c|l|c|}
\hline$\#$ & Route & Score \\
\hline 1 & $0-2-5-7-8-9$ & 5 \\
\hline 2 & $0-3-6-7-8-9$ & 7 \\
\hline 3 & $0-3-6-8-9$ & 6 \\
\hline 4 & $0-3-6-9$ & 4 \\
\hline 5 & $0-1-4-6-9$ & 4 \\
\hline 6 & $\ldots$ & $\ldots$ \\
\hline
\end{tabular}
will always try to use it. Given the limited resources of the network, it can cause excessive load on the system. To solve the above problem is proposed to use a neural network (NN) [5].

Neural networks. NN can't be programmed in the traditional sense of the word, they should be educated (trained). The opportunity to study - gives one of the main advantages of NN DRP over traditional DRP algorithms. Technically, the training is to find the transmission factor between nodes. During training of NN is able to detect complex relationships between input and output data, and perform synthesis. This means that in case of successful training, the network is able to make the right decisions based on data that were not in the study sample, incomplete data or partially corrupted data.

Training of NN can be done by the following methods:

- $\quad$ training with teacher - output reactions of NN are known;

- learning without a teacher - NN output reactions forms on the basis of the input signal;

- reinforcement learning the system of rewards and penalties appointment from the external environment.

Training with teacher in this case is impossible, since the initial response of NN previously unknown. That is believed that the noise levels are acting on random nodes randomly.

Typically, learning without a teacher used only for problems with a known set of objects describing the training set where needed to determine the internal relationships, dependencies, patterns that exist between objects, so this method is also rejected.

Reinforcement learning does not involve prior knowledge of the initial reaction, and interaction occurs only with the environment. As a response to the interaction shaped reinforcement signal that enables uniquely identify the best routes of transmission of information at this stage of the network.

Given the specificity of sensory communication networks, use of reinforcement learning algorithm for NN learning is proposed.

Reinforcement learning. Reinforcement learning is a result of getting by an agent of rewards and penalties that come from the external environment (Fig. 2) [5].

In this situation, $x(t)$ the agent performs an action $a(t)$, obtains reinforcement $r(t)$ and enters the next situation $x(t+1), t=0,1,2,3, \ldots$. Reinforcement $r(t)$ can be positive (reward) and negative (penalty).

The purpose of agent is to maximize total reward, which will be available in the future.

There are two types of system with reinforcement. 
- Alpha-reinforcement system - the weight of the active connections changed to the same size and weight of inactive connections does not change its value.

- Beta-reinforcement system - the weight of all active connections initially changed to an equal value, and then from the weight of each connection subtracted total change of weight of active connections that was divided by the total number of connections.

The last type of system has the property of conservative relative weight, since this approach, the total weight of all connections remains unchanged. This property considers the amount of microcontroller memory for storing weight relations, so, taking into account limited resources, this type is better.

Dynamic routing the principles of neural networks._Given the fact that the structure of WSN has something in common with the structure of neural networks, use of appropriate principles of neural networks to optimize the DRP. To train neural network method of reinforcement learning has been chosen.

Consider an optimized DRP algorithm on the principles of neural networks. On the first stage should be constructed table-based routing metric, i.e. qualitative or quantitative assessments of routes. Assessment of route score should be determined by the conditions in which the network operates. If you know that environment has sources of powerful noise, you should use the qualitative assessment, otherwise quantify. The network starts according to the existing routing table, which in turn is complemented by the weight for each route. Initially, all routes will have the same weight. Then after every successfully delivered packet using appropriate route, to this route should be assigned a new value of weight - bigger than the previous. In case of no delivery confirmation or delivery of the corrupted packet, to the appropriate route is assigned a weight less than the previous. After some time $\mathrm{T}_{\text {lim }}$ weights will have higher priority than a metric (qualitative or quantitative) and optimal route is the one that has more weight. Thus sensor network dynamically adapts to changes in the external environment.

Conclusions. Demand of low power consumption for WSN in biotelemetry, structural parameters and equipment monitoring imposes several restrictions on the algorithms of speed communication.

Given the limited resources of WSN, using traditional dynamic routing can cause excessive load on the system caused by the absence of a mechanism that takes to account an errors on each route. Possible mismatch of the metric to the real environmental conditions can generate significant information network load because of the fact that router will constantly give a preference to suboptimal route, in terms of reliability.

The proposed DRP method based on neural networks can improve WSN through the introduction of additional mechanisms that takes into account an errors on the routes. This method allows to dynamically monitor the quality of routes and give preference to those routes that are presently optimal as analogue of least total electrical resistance definition for achieving of maximum current between the nodes.

1. Kutulowski M., Cichon J., Kubiak P. Algorithmic Aspects of Wireless Sensor Networks. - Poland, Wrozlaw: Springer, 2007.

2. Levis P., Madden S., Polastre J. TinyOS: An operating system for wireless sensor networks. - New York, NY: Springer-Verlag, 2005. - $374 \mathrm{p}$.

3. Moy, J. RFC 2328 "OSPF Version 2" // The Internet Society. - April, 1998.

4. Border Gateway Protocol. - Available at: http://www.cisco.com/ (accessed 12.01.2016)

5. Sutton R., Barto A.. Reinforcement Learning: An Introduction. - Cambridge: MIT Press, 1998.

6. Nilsson J.W., Riedel S.A. Electric Circuits, - Prentice Hall, 2011. - 794 p.

УДК 621.391

ДИНАМІЧНА МАРШРУТИЗАЦІЯ НА ОСНОВІ НЕЙРОННИХ МЕРЕЖ

Ю.С. Ямненко, докт.техн.наук, Ю.В. Хохлов, канд.техн.наук, О.В. Редько

Національний технічний університет України «Київський політехнічній інститут», пр. Перемоги, 37, Київ, 03056, Україна. e-mail: petergerya $@$ yahoo.com

Запропоновано метод динамічної мармрутизаиії, щуо базується на принципах функиіонування нейронних мереж, який дозволяє поліпшити роботу бездротової сенсорної мережі за рахунок впровадження додаткового механізму врахування рівня помилок на маршрутах. Дании метод дозволяє динамічно відстежувати якість маршрутів і віддавати перевагу оптимальними марирутам. Бібл. 6, табл. 2, рис. 2.

Ключові слова: бездротовий зв'язок, сенсорна мережа, IEEE 802.15.4, нейронна мережа, динамічна маршрутизація, автоматизація, оптимізація.

УДК 621.391

ДИНАМИЧЕСКАЯ МАРШРУТИЗАЦИЯ НА ОСНОВЕ НЕЙРОННЫХ СЕТЕЙ

Ю.С. Ямненко, докт.техн.наук, Ю.В. Хохлов, канд.техн.наук, О.В. Редько

Национальный технический университет Украины «Киевский политехнический институт»,

пр. Победы, 37, Киев-56, 03056, Украина.

e-mail: petergerya@yahoo.com

Предложен метод динамической маршрутизачии, базирующийся на принципах функционирования нейронных сетей, который позволяет улучшить работу беспроводной сенсорной сети за счет внедрения дополнительного механизма учета уровня ошибок на марирутах. Данный метод позволяет динамически отслеживать качество маршрутов, и отдавать предпочтение маршрутам, которые являются оптимальными. Библ. 6 , табл. 2, рис. 2.

Ключевые слова: беспроводная связь, сенсорная сеть, IEEE 802.15.4, нейронная сеть, динамическая маршрутизация, автоматизация, оптимизация.

Надійшла 28.01.2016 Остаточний варіант 16.05.2016 